\title{
Math and Equity in the Time of COVID: Teaching Challenges and Successes
}

\author{
Jennifer L. Ruef ${ }^{1 \star}\left(\right.$ D), C. James Willingham ${ }^{2}$ (D), Madeline R. Ahearn ${ }^{1}$ (1)
}

${ }^{1}$ University of Oregon, Eugene, OR, USA

2 James Madison University, Harrisonburg, VA, USA

*Corresponding Author: jruef@uoregon.edu

Citation: Ruef, J. L., Willingham, C. J., \& Ahearn, M. R. (2022). Math and Equity in the Time of COVID: Teaching Challenges and Successes. International Electronic Journal of Mathematics Education, 17(2), em0681. https://doi.org/10.29333/iejme/11818

ARTICLE INFO
Received: 19 Nov. 2021

Accepted: 16 Feb. 2022

\begin{abstract}
Background: This article describes teachers' equity concerns related to teaching mathematics online as a result of the COVID-19 pivot to online/distance-based instruction. COVID-19 restrictions forced the creation of virtual education contexts that magnified existing equity issues related to access to technology and the challenges of providing inquiry-based, student-centered instruction.

Methods: This study took place under conditions promulgated by the COVID-19 pandemic. Nine teachers agreed to share their observations and experiences with the sudden switch to teaching mathematics online. Our methods included two online open response surveys. We qualitatively analyzed the responses from the surveys, coding for a priori, and emergent themes (Charmaz, 1995; Emerson et al., 2011).

Findings: The results indicate that our participants experienced concerns for students and families struggling to effectively engage with and access online education, and shared the practices and online tools they found most and least helpful in enacting equitable instruction.

Contribution: This work sheds light on how skilled and caring teachers leveraged prior experiences, collegial support, and technological tools to meet the challenges brought by the sudden transition to online mathematics pedagogy.
\end{abstract}

Keywords: equity, COVID-19, online teaching, learning

\section{INTRODUCTION}

Equity concerns are central to the effective teaching and learning of mathematics (AMTE, 2017; Horn, 2012; NCTM, 2014, 2018; Ruef, 2021). We define equity in the teaching and learning of mathematics as the intentional work of broadening learning opportunities for all learners, and in particular, those traditionally marginalized in mathematics education. Historically, mathematics education has been gated by sociocultural barriers for students identified as female, low socioeconomic status, Black, Indigenous, or People of Color (BIPOC) (Gutiérrez, 2017; Goins, 2017; Horn, 2007; Langer-Osuna, 2011; Louie, 2017; Lubienski, 2002; Martin et al., 2010; Ruef, 2021). In short, mathematics teaching and learning has historically been exclusionary. Equitable mathematics teaching and learning is inclusive.

Effective teaching and learning of mathematics must explicitly address equity issues in order to reframe the culture of mathematics and open learning opportunities to all students (Ruef, 2021). Mathematics teacher education currently builds upon decades of research on how best to enact equitable teaching within brick-and-mortar classrooms, which was a worthy and challenging endeavor under pre-pandemic circumstances. The advent of COVID-19 precipitated a nearly instantaneous shift to online and distance instruction, which created a natural experiment that would not have otherwise been condoned, allowing comparisons between in-person and online teaching. In partnership with secondary mathematics teachers and district support teachers, we examined some of the anticipated and unanticipated challenges and successes that emerged from teaching mathematics for equity that emerged from the sudden transition to online mathematics pedagogy.

\section{LITERATURE REVIEW}

Synthesizing decades of research on effective teaching and learning, the National Council of Teachers of Mathematics (NCTM) and the Association of Mathematics Teacher Educators (AMTE) promote a common vision for mathematics teaching and learning (AMTE, 2017; NCTM, 2014, 2018). In this vision, students are partners in their own learning. They are positioned as capable 
sensemakers, entrusted with co-constructing, testing, and refining mathematical arguments. This process is public, and often takes place within small groups of students working collaboratively to explore a shared mathematical task (Cohen \& Lotan, 2014; Horn, 2012; Ruef, 2021). It is supported by opportunities for formative assessment, ways in which teachers elicit evidence of students' understandings and questions about mathematical concepts (Black \& Wiliam, 1998). Teachers must also be skilled facilitators of productive discourse, able to help manage productive struggle and select and refine appropriate mathematical tasks. Thus, teachers possess agency and authority to design and enact effective mathematics instruction, and students possess agency and authority to make sense of and validate mathematical arguments (Ruef, 2021). This is challenging work.

Attempting to recreate effective small group work, formatively assess student understandings, and facilitate productive discourse in an online setting is an extraordinary challenge in the most literal way: it is outside the ordinary. Many mathematics teachers and their students faced this challenge as they began to engage in online and distance instruction in the Spring of 2020. Although teachers may have made significant strides towards utilizing technology to improve their students' mathematical problem-solving experiences, technology has yet to meet many of the requirements of online public sensemaking (Borba et al., 2021).

The teaching and learning of mathematics in online settings is not a new concern (Jones \& Long, 2013; Pope \& Mangram, 2015; Thanheiser et al., 2020). Engelbrecht and Harding (2005) catalog many of the challenges of online teaching. These include limitations on opportunities to collaborate and communicate; cognitive tools; internet resources; online assessment; and instructor's abilities to facilitate learning. They reported problems such as teacher reluctance; isolation; and inexperience teaching and learning online. These challenges and their implications for equitable math teaching were illuminated by our study.

At this time, reports of the impact of COVID-19-related restrictions on equitable mathematical instruction are nascent. One report that relates to our study shared the ways two male Japanese students' mathematical identities shifted with their transition to online instruction (Uegatani et al., 2021). Their findings include that the students found it more challenging to interact with one another in online settings (Uegatani et al., 2021, p. 15).

Not all of [students] were necessarily willing to enter the online community. They were forced to learn online due to the pandemic. We believe that educational research must treat this phenomenon as an equity issue and continue to investigate how to support such students in future similar situations (Uegatani et al., 2021, p. 15).

This study also found that the students were challenged in finding new ways of connecting in online class settings, and that opportunities to learn were mediated by access to, and fluency with, technology.

Related studies on the challenges and successes of the sudden switch to online learning precipitated by COVID-19 include Jordaan and Havenga's (2021) examination of the experiences of 52 undergraduate education students in South Africa who collaborated in groups of four to complete a problem-based curriculum. While only nineteen of the students completed the curriculum, perhaps due to the overwhelming nature of the shift to online instruction, those that did reported satisfaction with their ability to choose their own form of synchronous online meeting (e.g., Zoom calls), work collaboratively, and the meaningful nature of the real-world problems. Challenges included "availability of data" and the quality of internet connections. Calder et al. (2021) reported on the experiences of three adult learners in New Zealand as they switched to online instruction. Challenges included finding physical space to work in homes suddenly converted to home offices, childcare, hardware, and internet stability. Additionally, Zoom call lectures were less engaging than in-person instruction and self-regulation required different forms of motivation and organization of time. Successes included relief from commuting to campus, use of online tools for informal communication in service of collaborative problem solving, and the role of reflection in synthesizing different solutions to problems.

Our study resonates with the findings of a companion research project to analyze opportunities in online teaching and learning for relational equity: "the care and consideration students and teachers must take with each other to build and sustain productive and collaborative cultures of learning (Boaler \& Staples, 2008; Ruef \& Torres, 2020). How teachers and students establish caring and productive learning relationships in online settings was a primary consideration of our research.

\section{CONCEPTUAL FRAMING}

Teachers skilled in facilitating in-person instruction rely upon opportunities for students to sit in small groups, share physical artifacts and representations, and in general collaborate with relative ease. In-person settings provide opportunities for instructors to gauge the progress of an entire class, observe evidence of learning and confusion, and fluidly respond to questions or prompt students to focus on particular aspects of sensemaking. Online settings allow for collaboration, but limit interactions and instructors' abilities to assess learning.

Our study conceptualizes teaching for equity in online settings as attending to who is able to participate and under what conditions. Student participation mediates opportunities for learning, which is further impacted by sociological, technical, and practical aspects that help or hinder students' abilities to connect and interact with teachers and peers in online mathematics classes. We also attend to teachers' opportunities to assess student learning, which are also mediated by opportunities to elicit and observe evidence of students' understanding in online settings. This framing captures the successes, surprises, and concerns of equitable instruction enacted upon the sudden transition to online mathematics pedagogy (Ruef, 2021). 
Table 1. Experience, roles, and participation in study by participant

\begin{tabular}{|c|c|c|c|c|c|}
\hline Pseudonym & Pronouns & Years of experience & Professional role & Initial survey & Follow-up survey \\
\hline Mr. Belton & $\mathrm{He} / \mathrm{his}$ & 2 & HS teacher & $\sqrt{ }$ & $\sqrt{ }$ \\
\hline Mx. Breck & They/them & 3 & HS SpEd teacher & $\sqrt{ }$ & \\
\hline Ms. Dane & She/hers & 1.5 & HS teacher & $\sqrt{ }$ & \\
\hline Ms. Huxley & She/hers & 6 & Support teacher & $\sqrt{ }$ & \\
\hline Ms. Piper & She/hers & 30 & Support teacher & $\sqrt{ }$ & \\
\hline Mr. Smithson & $\mathrm{He} / \mathrm{his}$ & 2 & MS teacher & $\sqrt{ }$ & \\
\hline Mr. Tine & $\mathrm{He} / \mathrm{his}$ & 1 & HS teacher & $\sqrt{ }$ & $\sqrt{ }$ \\
\hline Mr. Weber & $\mathrm{He} / \mathrm{his}$ & 16 & HS teacher & $\sqrt{ }$ & $\sqrt{ }$ \\
\hline Ms. Centis & She/hers & 10 & HS teacher & & $\sqrt{ }$ \\
\hline
\end{tabular}

Table 2. Survey questions on teaching mathematics for equity

\section{Initial survey questions}

Q1. What are the two most pressing problems you have experienced in teaching mathematics via distance/online? Were any surprising, and if so, why?

Q2. What successes have you experienced in teaching mathematics via distance/online? Were any surprising, and if so, why?

Q3. What equity considerations and concerns do you have about teaching mathematics via distance/online?

\section{Follow-up survey questions}

Q1. What are the two most pressing problems you have experienced in teaching mathematics via distance/online? Were any surprising, and if so, why?

Q4. Please describe what you did anticipate in adapting to teaching via

distance/online.

Q5. Please describe what you did not anticipate in adapting to teaching via distance/online.

Q6. With whom, and using what resources, have you solved problems Q4. With whom, and using what resources, have you solved problems related to teaching mathematics via distance/online? related to teaching mathematics via distance/online?

Q7. Please add anything else you would like to share. Q5. Please add anything else you would like to share.

\section{METHODS}

Our study leveraged a natural experiment as it unfolded, permitting comparisons between in-person and online teaching conditions. The sudden transition to online mathematics classes launched teachers into the challenges of replicating the best of their classroom teaching practices in an untested format: online instruction. As researchers accustomed to observing mathematics classrooms, we too pivoted to online interactions. This study is framed by the following research questions:

1. What equity considerations and concerns did the teachers experience in teaching mathematics online?

2. What successes have teachers experienced in teaching mathematics online?

3. With whom, and using what resources, have teachers solved problems related to teaching mathematics online?

\section{Participants and Context}

The study took place entirely online, and included secondary mathematics teachers and support teachers, sometimes knowns as math coaches, from communities in the Northwestern United States. The first and the second author invited teachers to participate in the study based on demonstrated commitments to teaching mathematics for equity, which were evidenced through completion of a teacher preparation program centered on teaching for social justice and equity or participation in previous research projects on curriculum development centered on equitable principles. Of the eighteen teachers invited, nine volunteered for the study. The teachers in the study all identify as white, which is representative of the local districts and student populations they served. All teacher names are pseudonyms. Inferring gender from the participants' pronouns, four identified as female, four as male, and one as gender non-binary. The teachers' years of mathematics education experience ranged from one to thirty years of service, averaging eight years (Table 1 ).

\section{Data Sources}

The study included an initial and follow-up survey, consisting of open response questions. We conducted the initial survey, comprised of seven questions, in May, 2020, and the follow-up version, comprised of five questions, in July, 2020. To pilot test the studies, we asked two mathematics education colleagues to take the survey and provide feedback. The surveys were revised based on that feedback, resulting in the questions shared in Table 2. Because potential participants were teaching both in online and distance settings, the survey refers to them as distance/online. Distance settings limited pedagogy to distribution and collection of paper packets of mathematics lessons. In practice, all nine participants were teaching online, which is why the distance/online language is reduced to online for the remainder of this report. 


\section{Analysis}

The unit of analysis for this study was a participant's response to a survey question. We first analyzed the survey responses by a priori themes drawn from the research questions and emergent themes gleaned from the data through a process of analytic memo writing (Charmaz, 1995; Weiss, 1995). In practice, this involved the first and the third author reading the responses to each survey question, compiling an outline of related themes, and discussing their memos to assess agreement and dissonance among themes (Emerson et al., 2011). Once these authors reached consensus on the emergent themes of the responses, the second author reviewed the data using these themes as an organizational tool, ensuring that the ideas expressed by the participants were captured through this coding. Author 1 then coded all responses using the coding scheme that emerged from the memo-ing process. Next, the authors discussed and revised the initial coding scheme and Author 1 re-coded the data set using the revised coding scheme (Appendix). Approximately $20 \%$ of the data was then coded by Author 2, with a result of inter-rater agreement of $94.1 \%$ and a Cohen's Kappa of .74. This level of agreement indicates substantial agreement. The narrative in the next section presents the results of this analysis, organized by theme, with participants' quotes supporting the analysis as appropriate.

\section{FINDINGS}

The study's findings are organized here by the themes that emerged from the analysis of the survey results, detailing the challenges and successes the teachers experienced in teaching online, followed by challenges and successes of teaching for equity.

\section{Challenges and Successes of Teaching Online}

In the initial survey, the participants indicated challenges they did and did not anticipate. Teachers had as little as one week to plan for and initiate online instruction. In the Spring of 2020, online instruction was predominantly asynchronous. This presented a total loss of small group interaction opportunities. Teachers reported that setting up intentional and structured routines, including the naming of assignments, use of graphic organizers, and formatting of online materials helped to mitigate uncertainty for students because they spent less time and energy looking for assignments and course materials. Despite this forethought, the teachers reported that many students and their families struggled to access and navigate online materials.

\section{Interacting with students}

Teachers anticipated challenges in supporting students in making sense of mathematics, and navigating from misconceptions to conceptual understanding. The loss of in-person communication and collaborative group work linked to concerns about decreased engagement from students, which negatively impacted inquiry-based pedagogy. In response to these concerns, the teachers perceived a need for flexibility. Ms. Piper shared that, "I anticipated that it was going to take a lot of flexibility to maneuver through all of the changes." Mr. Smithson summarized some of the biggest losses in moving to online spaces.

I suspect that the absence of positive feedback and subtle feedback in the classroom has actually done more harm than any negative experiences could. Isolation is a powerful thing, and when students get isolated in a struggle, it causes them to lose confidence. I used to think that when students said, "this is so hard" in the classroom that the comment was negatively influencing the classroom culture, but now I know that it actually is normalizing a real feeling when you are tackling something new. I miss hearing students say that and echo the feelings of struggle. Back when we were in a physical school, each day students analyze their homework and look to identify errors. One of the most beautiful moments is when one student gets enough courage to say to the person next to them quietly, "hey I got question ____ wrong, did you get that wrong?" The long pause happens and then the other students responds, "YES!" Then the echo happens throughout the room and suddenly that student is not alone. I miss days like this. I see now just how important feedback is for understanding and for the way students perceive themselves.

This poignant reflection on the loss of opportunities for students to share understandings was echoed in the teachers' challenges to formatively assess students in general. Mr. Belton shared that "It was challenging not having the luxury of group discussions." However, the teachers did find success in one-on-one online discussions and providing diagnostic feedback in the form of comments on asynchronous work.

There were also pleasant surprises, as some students increased their participation in the online setting. Some teachers used student feedback forms, such as "highs, lows, and goals," to elicit what was working, what was not, and how to best support the students' learning. "Highs" indicated what students thought was working well, lows the opposite, and goals indicated what the students were prioritizing. Ms. Dane wrote:

I was actually shocked by the first simple google form I sent out. I asked simple questions like what are you worried about with distance learning, what are your hopes \& fears. I was shocked because the information I got back was so actionable. I could immediately see who I should make a special contact with. Who needed extra attention or encouragement. It was much deeper than an in-class check in like hold up 5 fingers if you really got this ...

Ms. Dane made use of regular feedback from her students to modify and improve instruction. 


\section{Modifying content and instruction}

To accommodate a slower pace of instruction, the participants planned to deliver less content. In practice, this was accomplished by teams of teachers and support teachers coming to agreements on which content was essential, what could be let go, and when minimized content might need extra attention in future coursework. This included alignments within courses and across grades. There was general consensus on a lack of district level coordination for making content decisions and mixed sentiments about whether that was, or was not, helpful. Ms. Dane shared that:

The best thing the district did was mandate that all sections of the same class had to send out basically the same lessons. Without this mandate, I think my teaching teams would have done what was comfortable. But, since we HAVE to send out the same lessons, we HAVE to collaborate. We divided up the lessons by week. Each week one person writes the lessons \& materials and the others give input. This is HARD because we have to rely on others and we can't just be polite. If I don't like something or don't think it is effective for the students, I have to say something. Sometimes other teachers don't have materials done on the agreed to timing so it's harder to give input. But, we are all doing what we can and I believe in my peers.

The teachers reported that limited administrative oversight was paired with limited support from the district. Limited support was a hindrance, but limited oversight created opportunities for the teachers to make planning decisions. To be clear, the district's resources were stretched thin, as seemed to be the case for all educational resources during the pandemic. Our observation is that all educators and support staff were doing the best they could, with what was available, under extraordinarily challenging circumstances.

\section{Asynchronous online instruction and assessment}

To accommodate the asynchronous nature of instruction, instructional coaches provided review units and "choice boards" of mathematical activities to practicing teachers, who were then able to differentiate instruction for their students by offering different levels of mathematical challenge related to the same content. The choice boards thus provided greater agency to students, who decided which activities to pursue. Finding and creating motivating materials was both a priority and a challenge. The teachers reported creating new rhythms to daily classes to better fit online interactions for synchronous and asynchronous lessons. Teachers indicated that they made appointments to meet with students via Zoom, and reported successes in supporting students.

However, in many cases, access to online platforms that facilitated student-student collaboration through break-out rooms was either not available or challenging to support. Ms. Piper's concern that classroom teachers "are struggling connecting with students and having students have conversations with each other" was echoed by Mr. Tine's observation that there was a "loss of student-to-student connections" and "isolation" in the classroom. Despite these challenges, some teachers found that video conferences often created opportunities to engage in diagnostic interviews with students, allowing teachers to assess student learning and provide feedback to support them in making sense of mathematics.

\section{Technological tools}

Despite advances in graphing software, mathematics education retains its focus on pencil-and-paper activities. Shifting to online teaching pressed the teachers to find and create electronic interfaces and activities. The teachers reported researching and implementing online tools including organizational software, graphing utilities, interactive whiteboards, and premade instructional videos, along with mathematical activities from applications such as Desmos, Geogebra, Google, Khan Academy, Padlet, and Phet Colorado. However, as Mr. Tine wrote, "the tools for this job were not waiting for us on the shelf." This sentiment captured a common theme that teachers scrambled to create a simulacrum of effective brick-and-mortar instructional practices and manipulatives with these tools, and that some students struggled to access and work with these new online pedagogical approaches.

However, for some teachers, the introduction of interactive digital whiteboards leveled the playing field in terms of inherent teacher authority. As Mx. Breck shared:

I'm having a lot of success teaching mathematics electronically with the few students I have connected with. I'm not actually surprised by how well it's going. We can interact on the same digital whiteboard at the same time and that is incredibly useful. I think it encourages students to write and express their ideas. And it puts their writing on the same level with mine. There's no writing 'up on the board' that carries more authority.

When pedagogical and technological tools aligned, teachers found their online approaches to be broadly effective, providing a glimpse into their potential future utility.

\section{Anxiety and loss}

Across all the teachers, there was a strong sense of anxiety and loss. Given the very rapid nature of the transition, the teachers did not feel adequately supported in finding the materials and digital tools necessary to teach effectively online. Mathematics support teachers struggled, in some cases, to convince teachers to let go of content, and to find online tools and materials that were conceptual and inquiry-based rather than procedural and lecture-driven. By far, the greatest sorrow teachers expressed was over the loss of contact with students. Interacting online brought pleasant surprises, but also the loss of the kinds of feedback loops that supported productive struggle and positive mathematical dispositions. Mr. Belton shared 
The first problem was not being able to help students one on one except through zoom. This was a challenge since many students checked out and were unengaged making it near impossible to communicate with and others felt stress and anxiety from having to learn online which caused a disconnect. It is hard to get in the profession to be there for students and then have a situation occur where you can't be there for them.

These sentiments captured the collective sense of loss shared by all the participants.

\section{Teacher collaboration}

One positive outcome was strong collaboration between teachers within schools, specifically one middle and one high school, and between teachers and support teachers. Finding time to meet and co-plan, teachers distributed the burdens of making difficult decisions about which content to keep, preparing materials for instruction, and setting up online access for students. As Mr. Weber shared, "a huge success thus far has been the high level of collaboration between teachers in my department. We've built on curriculum level teams, and are meeting [multiple times weekly] to plan and write distance learning lessons." This sentiment was echoed by Mx. Breck, who found that collaboration and co-planning had led their department to "become a very cohesive unit."

However, these collaborations were not without challenges, as some teachers waited until "Sunday night" to upload content for use Monday morning, causing frustration for other members of their teaching teams. Additionally, as one teacher pointed out, there was no way to "shut the door" and teach as they saw fit, and colleagues varied in their willingness to hear and act upon constructive feedback. Having agreed to work together in lock step was thus both liberating and limiting.

\section{Summarizing challenges and successes of teaching online}

In summary, the teachers reported both challenges and successes in connecting with students online. The challenges stemmed from students' abilities access to technology and the ease with which they could fade from view and the loss of organic in-person interactions amongst students. The successes emerged from formerly shy students finding spaces in which to contribute and communicate via feedback forms. The teachers, four of whom collaborated in the same building, found their greatest successes in collaborating with other classroom and support teachers to modify content and instruction, eliminate content in order to streamline course sequences, and share planning and resources. The lack of support from the district was considered both a help, in affording teacher agency, and a hindrance, in limiting support and resources. The teachers initially engaged in asynchronous online instruction and found and created various technological tools to support and assess students' learning opportunities. The teachers also reported a sense of loss and anxiety as they faced limited engagement with, and processed the challenges faced by the students and their families.

\section{Challenges to Teaching for Equity}

While it might be argued that all challenges and successes shared in the previous section are equity concerns, the teachers and support teachers were asked to identify two specific challenges to teaching for equity. Most participants exceeded that number, and their responses were analyzed for common themes.

\section{Variation in home supports}

Varied access to technology, both internet access and devices, led to exacerbated gaps in opportunities for learning. The teachers reported that some students had family members who could support their learning, others did not. Some students had to share devices with siblings. Many students worked outside their homes or supported their families by providing care for younger siblings, while some families struggled with job loss or food or housing insecurity. The stresses of the pandemic were unequally distributed, as were the impacts on learning. Mr. Tine shared that:

Student access to reliable technology was never a given throughout the term. At least a third of my students who were regularly engaged in the entire duration of the term faced tech-related issues that got in the way of their learning. Internet access was often the issue, as was the sharing of devices in multi-student families. Additionally, we operate under the false assumption that students are tech savvy, they are not. They are social media savvy. If we want them to become outstanding online students, we need to teach them how to use the tools, which means teaching things like how to navigate multiple tabs, how to splitscreen, how to pin a tab or use bookmarks. Very basic computer skills that I was taught in middle school typing courses, and are no longer taught. If students come to the mathematics already frustrated by not being taught how to use their tech tools, our job becomes much harder. I would imagine that learning these basic computer skills at home is something skewed by family income/wealth, so it's just another barrier for many of our students.

A related challenge was the ability to communicate with families. Mr. Weber lamented the "loss of the land line," noting that it was difficult to reach students via another person's cell phone. Additionally, there were fifteen languages spoken among the high school student population, and translation of materials into other languages proved beyond the capacity of the strained system. Students' frustrations in accessing content were noted as a specific equity problem because of the variation in families' abilities to support students. This summation of technology issues captures observations shared by all the teachers.

\section{Access to school supports}

Given the demands of the quick transition to online instruction, Individualized Education Plans (IEPs) for Special Education (SpEd) students, and 504 plans (accommodation plans for non-SpEd students with identified educational needs) were particularly difficult to enact. Though the high school teachers reported that their collaboration relied strongly on the participation of an 
intervention supports teacher, this was at the planning level. In general, observing the requirements of IEPs and 504 plans proved daunting. Mr. Belton wrote that, "Students with IEPs definitely did not receive the support that they would normally get."

\section{Summary of challenges to equity}

In summary, the teachers reported variation in at-home access to technology and support and the demands on students to support their families. This variation impacted students' opportunities to learn. Relatedly, students varied in their ability to access at school supports, including accommodations for emergent bilingual students and those with IEPs and 504 plans.

\section{DISCUSSION}

The discussion begins with summaries of our findings organized by the research questions, followed by their contributions to research and pedagogy, and the limitations of the study. We conclude with our next steps as both educators and researchers.

\section{What Equity Considerations and Concerns did the Teachers Experience in Teaching Mathematics Online?}

The primary equity concerns reported by the teachers included access to technology, both in terms of devices and internet access, and navigating online systems to find content and activities (Uegatani et al., 2021). Specifically, the teachers noted the limitations of breakout rooms in online classes, which gated opportunities to observe and support productive small group discourse among students and opportunities for formative assessment (Black \& Wiliam, 1998; Calder et al., 2021; Ruef, 2021). These concerns were poignantly summarized by Mr. Belton, who wrote, "I do not like distance learning because it is a lot harder to create a relationship with students and be there for their needs when you cannot reach or talk to them." Additionally, the needs specified in 504 plans, IEPs, and translations for emergent bilingual students were harder to meet.

While the teachers were able to make creative use of existing technology, there is a clear and compelling need for better collaborative conceptual mathematical tools (Calder et al., 2021; Jones \& Long, 2013; Jordaan \& Havenga, 2021; Pope \& Mangram, 2015). For example, the Desmos activity builder, Padlet, and interactive whiteboards were all described as helpful to small group interactions. But while those tools supported conceptual learning, it remained challenging for teachers and students to re-create the fluid interactions of in-person small group work. The successes the teachers reported they had engineered to support student choice, engagement, and success reflected the teachers' commitments to teaching for equity. Together, they found ways to build community, fostering agency amongst communities of teachers and students in mathematics classes.

\section{What Successes have Teachers Experienced in Teaching Mathematics Online?}

The findings laid a clear and compelling case for the challenges faced by the teachers in our study. They also shed light on the teachers' ingenuity and perseverance in solving problems. Motivated by care and compassion for their students, these teachers appear to have built the best solutions possible under daunting circumstances (Calder et al., 2021; Jordaan \& Havenga, 2021). While schools and districts were hard pressed to provide the tools, training, and support teachers needed to pivot instruction to online settings, we can be heartened by the creative and collaborative response of these teachers. A colleague once joked that during a teaching job interview, she responded to the requisite question "What else would you like us to know?" by saying she was very skilled at "building things out of cardboard and duct tape." Teachers have, for far too long, had to make do with diminishing funds for education. The skills they have developed to continuously provide high quality instruction despite decreasing resources likely contributed to their creative and collaborative problem solving during the pandemic.

While some of the challenges proved difficult to solve, there were also unanticipated successes. Ms. Dane shared that

I did not anticipate how much more I would get to know about students who are generally shy or quiet in class. Most students seem comfortable sharing things online (like in our highs/lows/goals at the end of the week). Even my least engaged students will write something.

For many students, engagement in online learning was challenging, but there were also successes.

In our own work as mathematics teacher educators, we have observed the use of Zoom chat bars and polls as a way to engage multiple students in a whole class "discussion," in ways that we would have been challenged to enact in brick-and-mortar classrooms. Sometimes, as Mx. Breck and Ms. Dane noted, quieter voices emerge in online settings (Sun et al., 2022).

With Whom, and Using What Resources, have Teachers Solved Problems Related to Teaching Mathematics Online?

The teachers reported collaborating with colleagues in and outside of their schools, support teachers, administration, and most importantly, their students. The students were important partners in redesigning equitable mathematics education for online instruction. They provided feedback and evidence by which the teachers could assess the effectiveness of their instruction. Working in collaborative teams, the teachers modified curriculum by coming to consensus on what would be taught and when, and sharing the work of preparing lessons and assessments within course-based teams (e.g., Algebra or Geometry). Four of the nine participants were teachers in the same school, and their abilities to commiserate and collaborate were essential to their collective ability to support their students (Boaler \& Staples, 2008; Sun et al., 2022).

The teachers sought out, modified, and curated online resources for interactive mathematical problem solving. In practice, this involved posting mathematical tasks to online course sites (e.g., Canvas) for students to work on as individuals or in small groups via breakout rooms on Zoom calls (Calder et al., 2021). 


\section{Contributions to Research}

This study extends earlier research on teaching and learning mathematics for equity (Gutiérrez, 2017; Goins, 2017; Horn, 2007; Langer-Osuna, 2011; Louie, 2017; Lubienski, 2002; Martin et al., 2010; Ruef, 2021) by providing a sense of the specific challenges faced by secondary mathematics teachers and support teachers in online settings (Calder et al., 2021; Engelbrecht \& Harding, 2005; Jordaan \& Havenga, 2021). Additionally, our findings report the ways teachers collaborated to solve problems of practice under immediate and challenging circumstances.

Our use of online surveys allowed us to interact with teachers under challenging circumstances that included severe limitations of teachers' time and energy and inabilities to meet in person during the early months of the pandemic. Initially, we intended to conduct individual and group interviews via Zoom calls. In our own work as mathematics teacher educators, we quickly recognized the dangers of Zoom burnout. Conducting online interviews would have placed an undue burden on the study participants, so we pivoted to the use of short answer Qualtrics surveys that could be completed whenever the teachers might find the time and motivation to do so. In this way, outcomes of the pandemic shaped the methods for this study. One of our methodological contributions emerged from making a way past an impediment.

\section{Contributions to Pedagogy}

It is difficult to say much about what happened in the classrooms of our participants because of the methodology for this study. However, what we were able to observe, via the participants' responses, includes the surprising ways that students who might have been overlooked in brick-and-mortar classrooms emerged in online settings. This happened in chat rooms, in one-onone video calls, in break out rooms, and in the use of online whiteboards that democratized the power of the pen-all contributions were visually represented as equally present, and thus equally valued when shared in those ways (Boaler \& Staples, 2008; Jordaan \& Havenga, 2021).

The use of online requests for feedback from students on how they were doing, what they needed, and their hopes and goals for the course centered student experiences in new and important ways. The teachers' new fluency for online graphing and other representational software opened new ways for students to create and make sense of mathematical representations (Calder et al., 2021). This benefited all students, and in particular, those who struggled with fine motor skills. In general, any form of interaction that allowed teachers and students to connect, supported relationship building, and provided opportunities for formative assessment (Black \& Wiliam, 1998).

\section{Limitations}

While the teachers invited to take part in the study were chosen for their commitments and experience in teaching for equity, they also reflect the predominant racial group of the communities they represent. White people may effectively work for racial justice yet never fully understand the lived experience of people of color. As researchers in partnership with these teachers, we acknowledge this shared limitation.

Our greatest limitation framed our methods: the pandemic itself. Our interactions were, by necessity, conducted entirely online and asynchronously. Our access to actual classrooms was gated by the overwhelming demands on teachers and ourselves, as researchers and instructors, during the pandemic. In short, we made the best of what was available to us, in terms of access and data collection. Thus, our observational lenses were closely framed by the conditions that created the de-facto experimental conditions.

\section{Next Steps}

As we extend our research, we have secured grant funding to purchase and distribute document cameras to a cohort of preservice teacher candidates. In many ways, mathematics remains the province of pencil and paper. In the interim, as we wait for technology to better meet the demands of online collaboration, document cameras may provide a collaborative problemsolving platform that supplements conceptual inquiry-based pedagogy as a form of interactive technology. The document cameras can be used in Zoom meetings to share visual displays with peers. However, document cameras generally gate interactive spaces to one speaker at a time, in contrast to interactive whiteboards that support a different kind of collaboration, as students may post simultaneously. Additionally, they require access to stable internet connections of sufficient bandwidth. It could be of interest to observe the ways distributions of intellectual authority and agency are supported or stymied by different forms of student presentations in small and large group collaborations (Jordaan \& Havenga, 2021; Ruef, 2021).

We also collected data in answer to the question: "What's worth keeping?" as we migrate from online instruction to brick-andmortar classrooms. Our analysis of the participants' responses indicated that assessment of learning via online shared documents and tasks, technological tools that de-centralize mathematical authority, and interaction formats that allow and encourage multiple and simultaneous student contributions are all worth keeping (Sun et al., 2022). Technology can also support and organize alignments of curriculum within and across grade bands. The teachers in our study supported one another, and their students, to focus on big ideas and key concepts. Teachers who collaborate to select impactful content are answering the critique that mathematics curriculum in the United States is a mile wide and an inch deep. This is an important equity consideration. The long months of distance/online mathematics instruction were challenging. The lessons of the pandemic were hard-won, and collectively, we aim to improve our shared efforts to teach mathematics for equity.

\footnotetext{
Author contributions: All authors have sufficiently contributed to the study, and agreed with the results and conclusions.

Funding: No funding source is reported for this study.

Acknowledgements: The authors wish to thank the participants for sharing their experiences for our study.

Declaration of interest: No conflict of interest is declared by authors.
} 


\section{REFERENCES}

Association of Mathematics Teacher Educators. (2017). Standards for preparing teachers of mathematics. https://amte.net/standards

Black, P., \& Wiliam, D. (1998). Inside the black box: Raising standards through classroom assessment. Phi Delta Kappan. https://kappanonline.org/inside-the-black-box-raising-standards-through-classroom-assessment/

Borba M. C., Engelbrecht J., \& Llinares S. (2021). Using digital technology and blending to change the mathematics classroom and mathematics teacher education. In K. Hollebrands, R. Anderson, \& K. Oliver (Eds.), Online learning in mathematics education (pp. 21-42). Springer. https://doi.org/10.1007/978-3-030-80230-1_2

Calder, N., Jafri, M., \& Guo, L. (2021). Mathematics education students' experiences during lockdown: Managing collaboration in eLearning. Education Sciences, 11(4), 191. https://doi.org/10.3390/educsci11040191

Charmaz, K. (1995). Grounded theory. In J. A. Smith, R. Harre, \& L. Van Langenhove (Eds.), Rethinking methods in psychology (pp. 27-49). SAGE. https://doi.org/10.4135/9781446221792.n3

Cobb, P., Gresalfi, M., \& Hodge, L. L. (2009). An interpretive scheme for analyzing the identities that students develop in mathematics classrooms. Journal for Research in Mathematics Education, 40(1), 40-68. https://doi.org/10.5951/jresematheduc. 40.1.0040

Cohen, E., \& Lotan, R. (2014). Designing groupwork: Strategies for the heterogeneous classroom. Teachers College Press.

Emerson, R. M., Fretz, R. I, \& Shaw, L. L. (2011). Writing ethnographic field notes. University of Chicago Press. https://doi.org/10. 7208/chicago/9780226206868.001.0001

Engelbrecht, J., \& Harding, A. (2005). Teaching undergraduate mathematics on the Internet. Educational Studies in Mathematics, 58(2), 253-276. https://doi.org/10.1007/s10649-005-6456-3

Goins, E. (2017). Why I'm leaving a research I university for a liberal arts college. American mathematical society 'blog on inclusion/exclusion. https://blogs.ams.org/inclusionexclusion/2017/09/15/why-im-leaving-a-research-iuniversity-for-aliberal-arts-college/

Gutiérrez, R. (2017). Political conocimiento for teaching mathematics: Why teachers need it and how to develop it. In S. E. Kastberg, A.M. Tyminski, A. E. Lischka, \& W. B. Sanchez (Eds.), Building support for scholarly practices in mathematics methods (pp. 1138). IAP.

Horn, I. S. (2007). Fast kids, slow kids, lazy kids: Framing the mismatch problem in mathematics teachers' conversations. The Journal of the Learning Sciences, 16(1), 37-79. https://doi.org/10.1080/10508400709336942

Horn, I. S. (2012). Strength in numbers. National Council of Teachers of Mathematics.

Jessup N. A., Wolfe J. A., \& Kalinec-Craig, C. (2021). Rehumanizing mathematics education and building community for online learning. In K. Hollebrands, R. Anderson, \& K. Oliver (Eds.), Online learning in mathematics education (pp. 95-113). Springer. https://doi.org/10.1007/978-3-030-80230-1_5

Jones, S. J., \& Long, V. M. (2013). Learning equity between online and on-site mathematics courses. Journal of Online Learning \& Teaching, 9(1), 1-12. https://jolt.merlot.org/vol9no1/jones_0313.pdf

Jordaan, T., \& Havenga, M. (2021). The show must go on: Active online collaboration during COVID-19-Mathematics students solving real-world problems. In 13th International Symposium on Project Approaches in Engineering Education and 18th Active Learning in Engineering Education Workshop (pp. 49-56). Braga, Portugal. https://zenodo.org/record/5095292\#.Yg7J4DhBzZ4

Langer-Osuna, J. M. (2011). How Brianna became bossy and Kofi came out smart: Understanding the trajectories of identity and engagement for two group leaders in a project-based mathematics classroom. Canadian Journal of Science, Mathematics and Technology Education, 11(3), 207-225. https://doi.org/10.1080/14926156.2011.595881

Louie, N. L. (2017). The culture of exclusion in mathematics education and its persistence in equity-oriented teaching. Journal for Research in Mathematics Education, 48(5), 488-519. https://doi.org/10.5951/jresematheduc.48.5.0488

Lubienski, S. T. (2002). Research, reform, and equity in US mathematics education. Mathematical Thinking and Learning, 4(2-3), 103-125. https://doi.org/10.1207/S15327833MTL04023_2

Martin, D. B., Gholson, M. L., \& Leonard, J. (2010). Mathematics as gatekeeper: Power and privilege in the production of knowledge. Journal of Urban Mathematics Education, 3(2), 12-24.

National Council of Teachers of Mathematics. (2014). Principles to actions: Ensuring mathematical success for all. National Council of Teachers of Mathematics.

National Council of Teachers of Mathematics. (2018). Catalyzing change in high school mathematics: Initiating critical conversations. National Council of Teachers of Mathematics.

Pope, H., \& Mangram, C. (2015). Wuzzit trouble: The influence of a digital math game on student number sense. International Journal of Serious Games, 2(4). https://doi.org/10.17083/ijsg.v2i4.88

Ruef, J. (2021). How Ms. Mayen and her students co-constructed "good at math." Journal for Research in Mathematics Education, 52(2), 152-188. https://doi.org/10.5951/jresematheduc-2020-0264

Ruef, J., \& Torres, A. (2020). A menu of risk-taking Scaffolds. Mathematics Teacher: Teaching and Learning PK-12, 113(9), 723-730. https://doi.org/10.5951/MTLT.2019.0091 
Sun, K. L., Ruef, J., Stoehr, K. J., Ahearn, M. (2022). Teaching preservice mathematics teachers in the time of COVID: What's worth keeping? Journal of Humanistic Mathematics. 12(1), 187-209. https://scholarship.claremont.edu/jhm/vol12/iss1/14

Thanheiser, E., Jones, D., \& Amidon, J. (Hosts). (2020-present). Teaching math teaching [Audio podcast]. Episode 10: Equity in synchronous online teaching, with de Araujo, Z. https://www.teachingmathteachingpodcast.com/10?fbclid= IwAR33orrFLalgABUloKO-cqq4uYrdMBk9FYp_Xu2ghpGN9zd-azuyiEwdEBA

Uegatani, Y., Nakawa, N., \& Kosaka, M. (2021). Changes to tenth-grade Japanese students' identities in mathematics learning during the COVID-19 pandemic. International Electronic Journal of Mathematics Education, 16(2), em0638. https://doi.org/10.29333/iejme/10905

Weiss, R. (1995). Learning from strangers: The art and method of qualitative research interview studies. Free Press. 


\section{APPENDIX}

\section{Coding Scheme}

RQs:

What equity considerations and concerns did the teachers experience in teaching mathematics online? What successes have teachers experienced in teaching mathematics online?

\section{Revised code book}

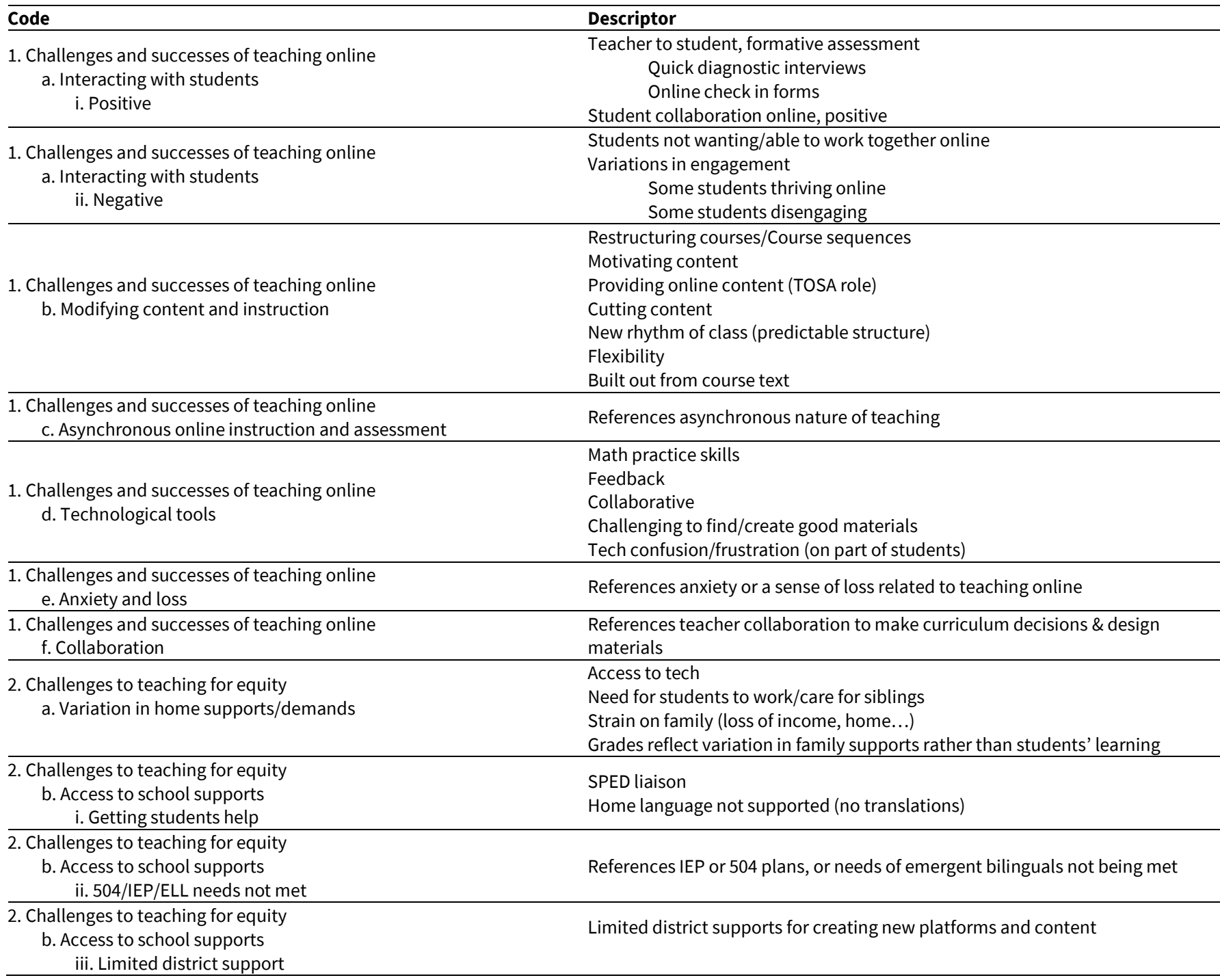

\section{Sample of Coded Data}

\section{7 items randomly selected from 83 total items and coded:}

\section{Rater 2 | Rater 1}

\section{Revised coding scheme:}

IRA 94.1\% || CK .74, substantial agreement

Post 1D-There's a time lag between teacher and student in distance learning. It was difficult to answer questions clearly through email or other text media. It was impossible for me to feel efficient when attempting to do so. When I was able to connect with a student through online video, I could share images/diagrams/graphs while explaining and responding to questions. The second pressing problem that occurs to me is that this only worked with students who had the tech resources and home space to access the lessons and get into them. Contacting students who had not engaged was often an exercise in frustration, sometimes even futility. If there was no response from student or family, I had no way of knowing what was going on with the student's learning or life.

Codes: 1c, 2a, 1aii | 1ai, 2a 
Pre 2G-I'm working on plans for review units for the fall and teachers have given me feedback that this would be helpful for them. I've also been creating weekly "Choice Boards" [so] that teachers can provide to families as supplemental learning so that way teachers don't have to create it themselves.

\section{Codes: $\mathbf{1 b} \mid \mathbf{1 b}$}

Post 5I-This dramatic shift was extremely stressful and done quickly with little to no training, I had a slight advantage over my peers in our building as I am the teacher of record for the online math classes, but I struggled to keep on top of the number of students assigned that included credit recovery kids who I didn't have a scheduled time to meet with them so they struggled more to make time to get help from me. Need more training and better tech-especially in how to assist students who are isolated.

Codes: 1ai, 1e $\mid 2 a$

Post 3D-Even though my district put great efforts to get computers or tablets and hot-spots to student without reliable access to tech, this only addressed only aspect regarding equity. We had to be aware of the non-academic demands on the lives of students navigating poverty, we had to find ways to meet the accommodations for students with learning disabilities. I had students who had to move houses, work jobs, care for family members, stress about wellness, and take other classes in addition to needing to learn about math at a distance. And this doesn't even bring in issues involving race and the impacts of a rising protest movement at a time of forced isolation. I have many concerns. It felt like the only real consideration I could make was to offer extended time and support for students who were lagging behind.

\section{Codes: $2 a \mid 2 a, 1 b$}

Post 2D-The number of kids I had who engaged (raw and percentage) was far higher than I expected. Almost all who responded to an end of class survey expressed that they had learned things. Perhaps my biggest surprise was the work with my colleagues. All teachers with common preps in my department (let me repeat: all) met in teams regularly via zoom to share planning, lessons, activities, etc. with each other. Not only sharing, there was a lot of back and forth between teachers to add/edit/augment various lessons or activities.

Codes: 1aii, 1f | 1aii, 1 f

Pre 1F-With my position, I would sometimes just find out where in the building a student is and go meet with them. Students didn't really have to seek me out. Now, though, it is almost entirely on students to access me. I have office hours and I've invited students individually to pop into my Zoom sessions. Still, I have had disturbingly few students access me. It was surprising to me how much harder it would be to connect with students when the burden of initiating that connection falls on them.

\section{Codes: 1ai, 1aii | 1ai, 1aii}

Pre 4C-I anticipated the general flow of an asynchronous online class given that I have been a student in that environment in undergrad, in terms of structuring weekly units to be accessible all at once at a regular time, with clear, fixed due dates and expectations for how to submit work; the new aspect in this case was being the teacher rather than the student.

\section{Codes: 1c | 1b}

Post 5A-I do not like distance learning because it is a lot harder to create a relationship with students and be there for their needs when you cannot reach or talk to them.

\section{Codes: 1ai | 1e, 1ai}

Post 3I-Access to reliable internet is an issue in our district and getting students to verbally engage when I can't "read" their body language meant I wasn't able to tell in a lot of cases how they were feeling or really doing.

Codes: 2a, 1ai | 2a, 1ai

Pre 6F-I have been working closely with the Algebra team at [MY HIGH SCHOOL]. Together with that team, we have addressed a number of thorny problems. They dove in and just started tackling this challenging endeavor. The Algebra team is four classroom teachers, me, and then a SpEd teacher. They are very focused on equity and access. It has been amazing to be a part of that team.

Codes: $1 \mathbf{f} \mid \mathbf{1 f}$

WWKG-My response is geared toward the district level, but here are a few things I hope to keep as we move forward:

- Hosting/holding regular collaboration times for teachers across the district via Zoom (especially for MS folks who don't have teaching partners in the same course)

- Sharing modules, lessons, assessments, etc in Canvas across buildings

- Continuing to implement priority standards, common assessments, and proficiency rubrics

Codes: 1f | $1 f$ 
Pre $1 \mathrm{E}-$ What I have heard from classroom teachers is that they are struggling connecting with students and having students have conversations with each other. Our district uses google classroom not Zoom and so break out rooms are not an option.

Codes: 1ai, 1aii | 1ai, 1aii

Post 4C-My subject area teams were crucial, each consisted of about 4-5 teachers, including myself. We had already been working collaboratively during the school year and that paid dividends in the spring. Additionally, I sought outside help from colleagues at other schools, and from former teachers and professors. As spring went on, in addition to Google Classroom and Desmos Activity Builder, I was often using equatlo (a google chrome extension for typesetting mathematics), the google docs/slides suite, loom (a screen recording app), and geogebra.

\section{Codes: 1f | 1f, 1d}

Pre 1A-Connecting with students and getting them help. Creating lessons that are engaging and exciting. Group Collaboration.

Codes: 1ai, 2b, 1b, 1aii | 1ai, 2b, 1bii

Post 3A-Students with IEPs definitely did not receive the support that they would normally get. Home life definitely became an issue as many students had to work to help support their families.

Codes: 2b, 2ai | 2b

Pre 2E-Teachers have shared that they are surprised by some students who are way more engaged in this format then they are in a traditional setting. I think they are surprised because they don't feel connected in this form.

Codes: 1ai, 1aii | 1aii

Post 1I-Getting students to ask for help or to interact with each other consistently. Really difficult getting to know students I had never met before-we started a new trimester using distant learning. Trying to reach some of them via any method was difficult and on a couple of occasions they didnt ever respond.

Codes: 1ai | 1ai, 1aii 